\title{
A rare association of total anomalous pulmonary venous connection and cor triatriatum
}

\author{
A rara associação de drenagem anômala total de veias pulmonares $e$ cor triatriatum
}

Ulisses Alexandre CROTI, Domingo Marcolino BRAILE, Moacir Fernandes de GODOY, Carlos Alberto DE MARCHI

RBCCV 44205-648

\section{Abstract}

The association between total anomalous pulmonary venous connection and cor triatriatum is extremely rare. We emphasize the possibility of rupturing the membrane of $\mathrm{cor}$ triatriatum in the preoperative cineangiographic study, providing a significant improvement of the clinical features, as well as surgical correction and successful evolution.

Descriptors: Heart defects, congenital, surgery. Heart atrium, abnormalities.

\section{Resumo}

A associação entre drenagem anômala total de veias pulmonares e cor triatriatum é extremamente rara. Enfatizamos a possibilidade de rotura da membrana do $c$ or triatriatum no estudo cineangiocardiográfico pré-operatório proporcionando melhora significativa do quadro clínico, assim como correção cirúrgica e evolução com sucesso.

Descritores: Cardiopatias congênitas, cirurgia. Átrio, cirurgia, anormalidades.

\footnotetext{
Work performed in the Hospital de Base da Medical School of São José do Rio Preto, SP, Brazil.

Correspondence address: Av. Brigadeiro Faria Lima, 5416 - Sala 07. São José do Rio Preto, SP, Brazil CEP: 15090-000.
} 


\section{INTRODUCTION}

The association between total anomalous pulmonary venous connection (TAPVC) and cor triatriatum (CT) is extremely rare [1], and successful corrective surgery has never previously been reported in the national literature.

Generally, TAPVP can be accompanied by patent ductus arteriosus, interventricular shunts, Fallot's tetralogy, double right ventricle outflow tracts and aortic arch interruption [2]. However, it is necessary to be aware of the possible coexistence of CT, which is characterized by the presence of a membrane that divides the left atrium in proximal and distal chambers, and might have one or more restrictive ostia [3].

We report on this rare association and the possibility of performing a pre-operative cineangiocardiography, thereby rupturing the CT membrane, giving improved hemodynamics, which permits adequate preoperative conditions to perform successful corrective surgery.

\section{CASEREPORT}

A male half-caste patient, C.E.V. from Minas Gerais State, Brazil was born prematurely at 32 weeks of gestation.

At four days old, he started with vomiting, cyanosis during breastfeeding and persistent tachypnea.

He was referred to our department at 1 month and 4 days with $4.2 \mathrm{~kg}$.

Cardiac auscultation presented with rhythmic sounds at two sinus nodes, tachycardia and hyper-phonetic, systodiastolic murmur $+++/ 6$ at the left sternum margin and lungs with vesicular murmur with stertor crackles at their bases.

The liver was $3 \mathrm{~cm}$ from the right costal edge and the patient suffered from cyanosis of the extremities (saturation of $78 \%$ ), dehydration and low cardiac output syndrome.

The thoracic radiograph evidenced significant pulmonary venous congestion and an increase in the cardiac area, with a cardiothoracic index of 0.78 .

The electrocardiogram evidenced significant right ventricular overload suggesting increases in the right atrium and ventricle.

The echocardiogram demonstrated TAPVP in the superior vena cava (supracardiac) with pulmonary hypertension, suspecting an association with CT, but it was impossible to give a definite diagnosis due to technical limitations.

The patient was sent for cineangiocardiographic study and for Rashkind's atrioseptostomy. Although there were difficulties to perform the procedure it was successfully achieved. We believe that rupture of the interatrial septum occurred (Figure 1). The pressure in the pulmonary branch was $42 / 35 / 41 \mathrm{mmHg}$, right ventricle $51 / 10 / 15 \mathrm{mmHg}$, right atrium $12 \mathrm{mmHg}$ and left atrium $7 \mathrm{mmHg}$. After the procedure, the right and left atria presented with equal pressures of 11 $\mathrm{mmHg}$, hemodynamic improvement $(80 / 40 \mathrm{mmHg}$ to $100 / 60$ $\mathrm{mmHg}$ ) and oximetry ( $80 \%$ to $93 \%$ ). The pulmonary branch was dilated, showing confluent pulmonary branches without stenosis. The venous return was abnormal via a common collector tube which emptied in the innominate and superior vena cava through a vertical vein, with a dilated route without signs of obstruction (Figure 2). The left atrium called our attention by presenting a reduced size, without limitations to contrast. No passage of contrast was seen to the right atrium.

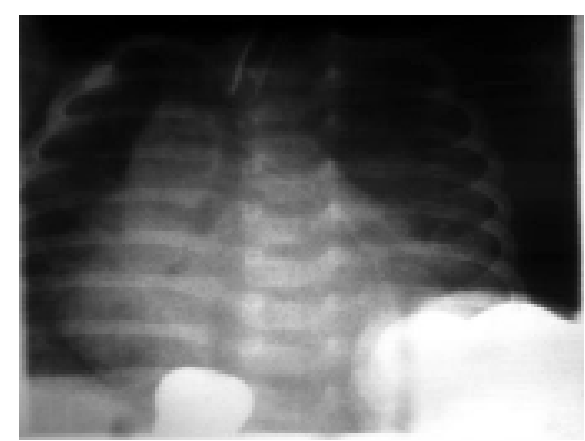

Fig. 1 - Rupture by balloon of the cor triatriatum membrane

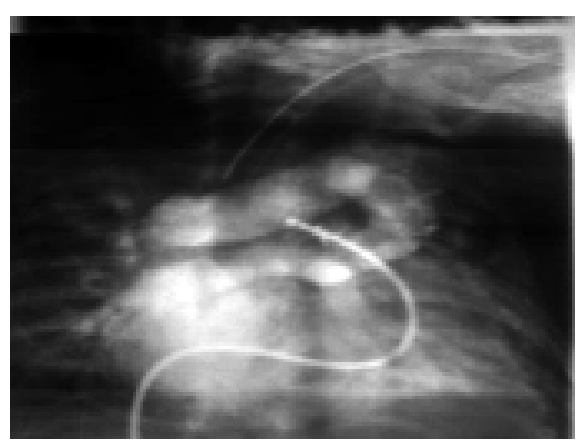

Fig. 2 - Cineangiocardiographic study demonstrating the venous return of the total anomalous pulmonary venous connection of the pulmonary veins in the superior vena cava (supracardiac)

The operation was performed two days after the cineangiocardiogram, with deep hypothermia and total cardiac arrest. The time of cardiopulmonary bypass (CPB) was 240 minutes ( 202 and 38 minutes) and the myocardial ischemia time was 130 minutes, with 9 minutes of total cardiac arrest at $18^{\circ} \mathrm{C}$

The right atrium was opened and an interatrial shunt of a moderate size and with thick edges was found near to the inferior vena cava. Amplifying the interatrial septum 
longitudinally, a fine membrane could be seen that had occluded the mitral valvar orifice, and which presented with a rupture and fissures. This we concluded had occurred during the preoperative hemodynamic procedure. This membrane divided the left atrium in two sections characterizing the presence of CT. After careful resection of this membrane near the mitral valve, it was possible to adequately identify all the portions of the left atrium, which was very small. Thus, we chose an approach by the transverse sinus. On opening the posterior wall of the left atrium, the common pulmonary venous branch (collector tube) was identified, which was opened transversally, thus enabling the anastomosis of the posterior wall of the left atrium with the anterior face of the collector tube. The ligature of the vertical vein was performed near to the innominate vein.

Concluding the main operating phase, the patient was maintained hemodynamically stable during 20 minutes, until he presented with arrhythmia and required CPB support for another 38 minutes to correct metabolic disturbances and optimization of the inotropic drugs.

In the postoperative period, the patient developed with an excess of pulmonary secretion, pneumonia and superficial dehiscence of the wound of the operation, treated with specific antibiotic therapy and was released from hospital on the 19th postoperative day.

Six months after the corrective surgery, the child presented with functional I (NYHA) without medications. The echocardiogram demonstrated slight functional tricuspid insufficiency and systolic pressure in the right ventricle of $37 \mathrm{mmHg}$, without evidence of stenosis in the pulmonary veins.

\section{COMMENTS}

TAPVP occurs in approximately $1.5 \%$ to $3 \%$ of patients with congenital heart disease [4] and CT in $0.1 \%$ [5], thus this association is extremely rare.

The clinical signs of isolated TAPVP or of CT are similar In TAPVP tachypnea, varying degrees of hypoxemia, metabolic acidosis are evidenced and the thoracic radiogram presents with a diffuse alveolar pattern. In CT, signs of tachypnea, paleness, low cardiac output and pulmonary venous hypertension are also seen, however it depends on the orifice of the membrane and the degree of obstruction. Thus, diagnosis of the association between these two anomalies should always be suspected when there are signs suggestive of pulmonary venous congestion.

TAPVP is classified according with the location of the connection in a supracardiac, cardiac or infracardiac position or mixed [6]. The supracardiac form is the most common $(50 \%)$ and the connection can occur in the innominate vein the azygos vein or the superior vena cava as in this patient. The echocardiogram demonstrated supracardiac TAPVP, but there were difficulties to confirm the diagnosis of CT [6], which had been suggested by the original physician that examined the patient and who referred the child for surgical treatment.

With the aim of defining the anatomical structures, reducing the pressure in the right atrium and improving the flow to the left chamber using Rashkind's atrioseptostomy, a cineangiocardiogram was indicated. Unfortunately, frequently the examination does not successfully demonstrate the abnormal membrane of CT in the left atrium

[7] and for this reason the immediate improvement in the clinical state, with an increase in the cardiac output and reduction of the pulmonary venous congestion was credited to the atrioseptostomy.

Special attention was given in the two days of the preoperative period, with hemodynamic and metabolic stabilization, fundamental for myocardial and renal preservation. The fact that we did not operate the child is an urgent character, surely influenced the result, as a high incidence of mortality can be associated with urgent operations [6].

In the intra-operative period, there was a great difficulty to identify the anatomic structures, a fact that explains the long time of CPB. As the initial diagnosis was TAPVP, we only realized that we were dealing with an association with $\mathrm{CT}$ when the restrictive membrane that covered all the mitral valve and divided the left atrium in two cavities was identified. At this point the membrane presented with a rupture and fissures. The defect in the interatrial septum was of moderate size and with well-defined edges. At this moment, we perceived that the rupture of the CT membrane had occurred during the cineangiocardiographic study and not during atrioseptostomy as the interatrial septum apparently did not demonstrate restricted flow.

The operative strategy using deep hypothermia and cardiac arrest was fundamental for the identification of the mitral valve and the opening of the CT diaphragm. Also it was essential at the moment of anastomosis of the left atrium with the pulmonary veins, eliminating the abnormal connections and closing the residual shunts [8]. The appropriate technique for the surgical correction was mandatory and produced good immediate and late results [9].

In conclusion, in patients with aforementioned clinical symptoms it is necessary to consider the diagnosis of TAPVP associated with $\mathrm{CT}$, even if the complimentary examinations do not clearly demonstrate this association. The possibility of the utilization of cineangiocardiographic studies in rupturing of the membrane and improvement of the clinical condition contributes highly and a complete operative correction optimizes the result. 


\section{BIBLIOGRAPHIC REFERENCES}

1. Vouhé PR, Baillot-Vernant F, Fermont L, Bical O, Leca F, Neveux JY. Cor triatriatum and total anomalous pulmonary venous connection: a rare, surgically correctable anomaly. J Thorac Cardiovasc Surg 1985; 90: 443-5.

2. DeLeon SY, Gidding SS, Ilbawi MN, Idriss FS, Muster AJ, Cole RB et al. Surgical management of infants with complex cardiac anomalies associated with reduced pulmonary blood flow and total anomalous pulmonary venous drainage. Ann Thorac Surg 1987; 43: 207-11.

3. Hess J, Brenken U, Eygelaar A, Martins FM. Successfu management of cor triatriatum associated with anomalous pulmonary / systemic venous connection in an infant. Pediatr Cardiol $1982 \cdot 2 \cdot 319-22$

4. Kirklin JW, Barratt-Boyes BG. Cardiac surgery. $2^{\mathrm{a}}$ ed. New York: Churchill Livingstone, 1993. p.651.
5. Alexi-Meskishvili V, Ovroutski S, Dähnert I, Fischer T. Correction of cor triatriatum sinistrum in a Jehovah's Witness infant. Eur J Cardiothorac Surg 2000; 18: 724-6.

6. Choudhary SK, Bhan A, Sharma R, Mathur A, Airan B, Saxena A et al. Repair of total anomalous pulmonary venous connection in infancy: experience from a developing country. Ann Thorac Surg 1999; 68: 155-9.

7. Richardson JV, Doty DB, Siewers RD, Zuberbuhler JR. Cor triatriatum (subdivided left atrium). J Thorac Cardiovasc Surg 1981; 81: 232-8.

8. Salomone G, Tiraboschi R, Bianchi T, Ferri F, Crippa M, Parenzan L. Cor triatritum: clinical presentation and operative results. J Thorac Cardiovasc Surg 1991; 101: 1088-92.

9. Giamberti A, Deanfield JE, Anderson RH, de Leval MR. Totally anomalous pulmonary venous connection directly to the superior caval vein. Eur J Cardiothorac Surg 2002; 21: 474-7. 